Article

\title{
Quantifying Road-Network Robustness toward Flood-Resilient Transportation Systems
}

\author{
Suchat Tachaudomdach ${ }^{1}$, Auttawit Upayokin ${ }^{2,3}$, Nopadon Kronprasert ${ }^{2,3}$ and Kriangkrai Arunotayanun ${ }^{2,3, *(D)}$ \\ 1 Ph.D. Degree Program in Faculty of Engineering, Chiang Mai University, Chiang Mai 50200, Thailand; \\ suchat_tac@cmu.ac.th \\ 2 Excellence Center in Infrastructure Technology and Transportation Engineering (ExCITE), Faculty of \\ Engineering, Chiang Mai University, Chiang Mai 50200, Thailand; auttawit.u@cmu.ac.th (A.U.); \\ nopkron@eng.cmu.ac.th (N.K.) \\ 3 Department of Civil Engineering, Faculty of Engineering, Chiang Mai University, Chiang Mai 50200, Thailand \\ * Correspondence: kriangkrai@eng.cmu.ac.th
}

Citation: Tachaudomdach, S.; Upayokin, A.; Kronprasert, N.; Arunotayanun, K. Quantifying Road-Network Robustness toward Flood-Resilient Transportation Systems. Sustainability 2021, 13, 3172. https://doi.org/10.3390/su13063172

Academic Editor: Gino D'Ovidio

Received: 9 February 2021

Accepted: 12 March 2021

Published: 13 March 2021

Publisher's Note: MDPI stays neutral with regard to jurisdictional claims in published maps and institutional affiliations.

Copyright: (c) 2021 by the authors. Licensee MDPI, Basel, Switzerland. This article is an open access article distributed under the terms and conditions of the Creative Commons Attribution (CC BY) license (https:/ / creativecommons.org/licenses/by/ $4.0 /)$.

\begin{abstract}
Amidst sudden and unprecedented increases in the severity and frequency of climatechange-induced natural disasters, building critical infrastructure resilience has become a prominent policy issue globally for reducing disaster risks. Sustainable measures and procedures to strengthen preparedness, response, and recovery of infrastructures are urgently needed, but the standard for measuring such resilient elements has yet to be consensually developed. This study was undertaken with an aim to quantitatively measure transportation infrastructure robustness, a proactive dimension of resilience capacities and capabilities to withstand disasters; in this case, floods. A four-stage analytical framework was empirically implemented: (1) specifying the system and disturbance (i.e., road network and flood risks in Chiang Mai, Thailand), (2) illustrating the system response using the damaged area as a function of floodwater levels and protection measures, (3) determining recovery thresholds based on land use and system functionality, and (4) quantifying robustness through the application of edge- and node-betweenness centrality models. Various quantifiable indicators of transportation robustness can be revealed; not only flood-damaged areas commonly considered in flood-risk management and spatial planning, but also the numbers of affected traffic links, nodes, and cars are highly valuable for transportation planning in achieving sustainable flood-resilient transportation systems.
\end{abstract}

Keywords: transportation resilience; flood-risk assessment; natural disasters; betweenness centrality; road-network robustness; humanitarian logistics; travel demand; transportation infrastructure; disaster-risk reduction

\section{Introduction}

Floods, the most frequent natural disasters, have been considerably increasing in frequency and severity over recent decades [1]. Flooding has a significant impact on human well-being and ecosystem function. Flood impacts vary depending on a variety of factors: length, depth, size, and velocity, as well as the risks and significance of the environment affected by situation and structure. Floods can take a few days or longer to affect people, communities, society, finances, and the natural environment. There are two types of losses from floods: direct and indirect. Direct losses are from contact with floodwater related to buildings, harvests, farm animals, cars, transportation, lives and injuries, loss of souvenirs, harm to cultural or heritage sites, and biological destruction. It has been evident that at least one-third of all losses due to natural forces worldwide are caused by floods [2]. Indirect losses are due to floodwater related to the loss of added value in businesses and disruption of industry, ecological loss, and disruption of transportation. Indirect losses also are the loss of added value in trade and business interruption, the legal 
costs associated with lawsuits, stress and anxiety, disruption to life, loss of community, loss of ecological resources, and disruption of transportation [3,4].

There are four types of flood in general: (1) local floods, which occur during the rainy season due to heavy rainfall; (2) riverine floods, which are caused by extensive flooding and prolonged flooding; (3) coastal floods, which are caused by sea levels rising above normal; and (4) flash floods, which are caused by the accumulation and runoff drainage of rainfall from upstream mountains. Flash floods are the most severe, and local floods have the least impact. When flooding occurs, all types of floods will impact the economy, the health system, and the transportation system. In Thailand, for example, the monsoon season typically takes place from July to October. River floods and flash floods can occur nearly every year throughout the northern and central region along the Ping and Chao Phraya river basins, covering almost one-third of the country. In July and August 2011, this part of Thailand unfortunately encountered the worst flood in half a century. The heavier-than-usual amount of rainfall was not the only factor responsible for this. It was reported that, as influenced by the lack of coordinated flood management and information supported, the local governmental agencies faced difficulties in their decision-making on mitigation during flooding situations and how to handle transportation [5].

Transportation-infrastructure systems, as one of the key critical infrastructures, are central for functioning economic progression and urban growth. The physical components within the systems include infrastructure (i.e., guideways, terminals, and stations), vehicles, equipment, fuel, power systems, and control-communications-location systems [6]. During floods, all these elements can be directly or indirectly damaged. Damaged transportation roadway networks during flood events can retard economic growth due to the inability of logistic trade. Humanitarian logistics and disaster-relief supply-chain operations can be severely hindered, leading to more human suffering and death. It has also been mentioned that transportation networks are among the most important types of infrastructure systems [7].

Despite that, there has currently been no direct way to measure the robustness of transportation, a proactive dimension of the resilience capacities and capabilities of transportation systems to withstand natural disasters. It is therefore difficult to improve the robustness in the absence of standardized measuring approaches [8]. As a general standard for selecting or prioritizing measures to diminish flood risks, several critical decision criteria need to be considered, including the cost-effectiveness of the measurement, the ratio between functioning and preservation costs, and the reduction in expected flood risk.

Although it has been very common to quantify and express flood risk using a single number, such an approach is rather incapable of certainly specifying how severe the flood impact will be and when flooding will occur. De Bruijn [9] investigated the flood-risk predictions from a system perspective by adopting a comparative approach to explore the concept of resilience and study how low-lying river systems respond to river-water discharge. De Brujin [9] suggested that the system's approach may expand the scope of the flood-risk-mitigation measures considered, as system dynamics are better understood. Moreover, to measure flood risks and robustness of the systems, different interpretations can be found. Some studies regard robustness as flexibility, while others associate it with the strength to endure changes [10]. Without any universally consensual description and interpretation, there is likely to be a threat of miscommunication between stakeholders. Mens et al. [11] proposed the concept of strength or robustness in flood-risk management. It is expected that analysis of the robustness of the flood risk system will help to understand the differences in the effects of flooding.

Due to the lack of a standard approach to assess the readiness of flood-risk management and efficiency of transportation infrastructure during flood events, this study developed a framework for analyzing the robustness of systems, especially the flood risk systems. The framework is based on a set of theories describing system behavior, critical aspects of system behavior, and a set of indicators to evaluate these characteristics. The scope of this study was conducted in a research field of local flooding and its impact empirically 
based on the transportation system in Chiang Mai, the largest city in the northern part of Thailand, one of the most flood-prone Southeast Asian countries. We have employed this framework for a flood-risk system to identify the areas at risk of flooding and to prepare flood-risk maps for developing flood-risk-management plans.

\section{Literature Review}

\subsection{Flood-Risk Systems}

A flood-risk system can be demonstrated by a geographic zone along a river that is prone to flooding. The system consists of socioeconomic and social components, and biophysical subsystems such as soil, water, plants, and animals, as well as upgrading floodprone areas and natural elements to control flood risks, such as dams. The socioeconomic subsystem also consists of the financial situation of the area, the economic value of land use, and the economic connection to other areas. It also includes people living in flood-prone areas [1]. Sea storms, waves in river-water reservoirs, or heavy rainfall can cause flash flooding from time to time, most of which are unlikely to cause significant damage and death. In addition to flooding, the work of the flood-risk systems (work, living, restoration, manufacturing) may be disrupted by other influences such as financial crises, disease, and war. These factors are essential to reflect, as they can adversely affect the inflexibility of the system against flooding.

From the literature reviews, we know that transport infrastructure, as a core component of urban infrastructure, plays a key role in critical emergencies such as natural disasters and extreme events [4]. Many researchers are interested in assessing the strength of the transportation system. For example, Valenzuela et al. [12] developed decision algorithms and risk-assessment frameworks to investigate the resilience of highway and pavement structures in response to extreme weather events. Considering that the pavement-structure performance is substantially affected by environmental factors, the resilience of the infrastructure resilience is therefore a key contributor to the sustainability of the systems. Other studies are presented in Table 1.

Table 1. Indicators for assessing robustness of transportation from previous studies.

\begin{tabular}{|c|c|c|}
\hline No. & Indicators for Assessing Robustness of Transportation & Studies \\
\hline 1 & $\begin{array}{l}\text { Different link-based capacity-disruption values for identifying } \\
\text { and ranking the most critical links and quantifying network } \\
\text { robustness in a transportation network }\end{array}$ & [13] \\
\hline 2 & $\begin{array}{l}\text { The ability to remain functional under a range of disturbances } \\
\text { (system response curve) }\end{array}$ & [11] \\
\hline 3 & $\begin{array}{l}\text { A network's maximum resilience level while simultaneously } \\
\text { determining the optimal set of preparedness and } \\
\text { recovery actions }\end{array}$ & [14] \\
\hline 4 & $\begin{array}{l}\text { Real trip distribution; each link in the network is measured } \\
\text { for criticality }\end{array}$ & [15] \\
\hline 5 & $\begin{array}{l}\text { Adaptability and transformability, and identifying important } \\
\text { components to implement resilience strategies }\end{array}$ & [16] \\
\hline 6 & $\begin{array}{c}\text { Transportation system performance, along with its } \\
\text { management; physical damage resulting from a future } \\
\text { hazard event }\end{array}$ & [17] \\
\hline 7 & Social, economic, and ecological resilience & [4] \\
\hline 8 & $\begin{array}{c}\text { The number of real trips that can be completed (using travel } \\
\text { demand data), Geographical Information System properties, } \\
\text { and network topological indicators }\end{array}$ & [18] \\
\hline 9 & Community-level resilience & [19] \\
\hline 10 & Level of loss and recovery time & [20] \\
\hline
\end{tabular}


Previous research has shown that although there are variations in assessing the robustness of transportation, almost none assessed the robustness of transportation while considering the damage or the impact of flooding at each level. Therefore, we intend to bridge the gap of the above-mentioned studies by quantitatively measuring the robustness of transportation against flooding disasters. This can be achieved by assessing, for each of the different levels of floods, the damaged area, the number of affected links, the number of affected nodes, and the number of the affected cars (in passenger car units; PCUs) as indicators of robustness.

\subsection{Transportation Resilience}

Currently, research on the resilience of transportation is available, but limited. However, previous research, which has been published in small numbers, has been very interested in robustness against flooding. This is a huge problem and has many impacts on economic systems and social, health, and educational aspects, as mentioned in Section 2.1.

As indicated by Carpenter, Walker, Anderies, and Abel [21], resilience refers to the capability to respond, improve, and remain as close as possible to the origin. As originally derived from the Latin "robustus", meaning strong and hardy, the robustness of the system can sometimes be expressed as a function of response and recovery. Several studies aimed to determine road-network resilience during flooding. They assessed the behavior of road networks during crises in which segments were disabled or unusable for a time. The proposed method was structured around two metrics calculated from the road network and trip distribution: network continuity and efficiency of alternative [22]. Some studies have shown a model of resilience since it is associated with seismic-resistance measures. Bruneau et al. [23] illustrated the concept of defining resilience over time from a single event $\left(a t t_{0}\right)$ and restoring the level of service to $100 \%\left(a t t_{1}\right)$, as shown in Figure 1.

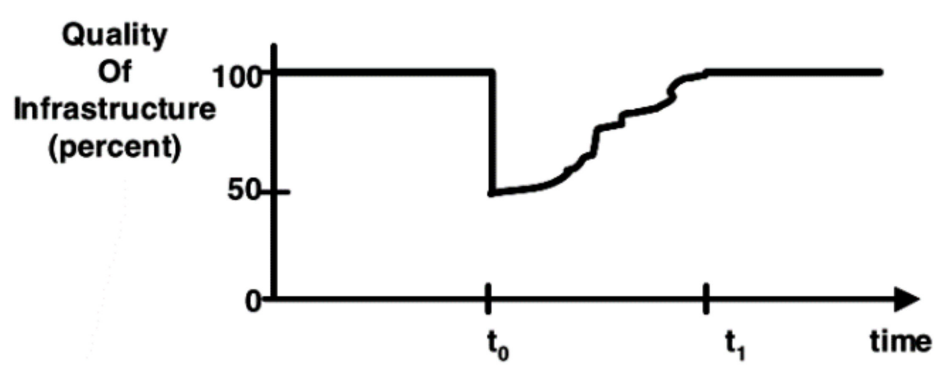

Figure 1. Conceptual measurement of resilience [23].

The previous studies indicated that the principles of measuring the resilience of transportation could be divided into two dimensions: technical and organizational. The technical dimension includes robustness, redundancy, safe-to-fail, and change-readiness, while the organizational dimension includes networks, leadership, culture, readiness, rapid recovery, absorbing externally induced changes, and cost-effectiveness [6,17,19,23-27]. Most studies have intended to measure robustness as a capacity requirement for network strength or resilience $[19,26,27]$. In this study, the robustness of transportation systems will be assessed with the sense of the capability of the strength of transportation infrastructure to withstand flooding disasters.

\subsection{Definition of System Robustness}

In literature, the term "robustness" can be found in various research contexts and has been given diverse meanings. The system robustness or system strength, which is rather common in engineering context, refers to the capability of organizations to keep some anticipated system characteristics under pressure [28-30]. The strength of decision-making, which is rather common in political decisions by analyzing policy and economics, was widely used as a basis for decisions under uncertainty [31-34]. 
Robustness can also refer to, for example, the ability to resist "imprecision" [35], the tolerance for "a certain degree of uncertainty" [36], and the potential to "manage with unexpected problems without major changes" [37]. Kermanshah and Derrible [18] suggested that strength in space systems, such as road networks, depends on many factors, including system size (number of nodes and links) and network-topology composition. Cats and Jenelius [38] indicated that capacity improvements would be more useful for increasing transport-system robustness. They evaluated public transport network robustness by using four steps: (1) define the sections of the public transport networks (PTN) model, (2) present the standards for assessing the impact of interruption of the link, (3) propose a structure for the most efficient capability optimization strategy during severe trouble conditions, and (4) study the potential of rising production capability in a price appraisal model that does not generate advantages. Moreover, Sullivan et al. [13] indicated that determining the network robustness index (NRI) values across all definite links and then allocating that sum by the total trip demand in the network can be used to measure the network trip robustness (NTR).

Kermanshah and Derrible [18] suggested that robustness can be evaluated using the percentage of losses in the infrastructure, including: (1) the number of vertices affected, $\Delta V$, such as critical point loss; (2) the number of edges affected, $\Delta E$, such as loss of road section number; and (3) total length (in meters) of affected roads, $\Delta L$. These qualities can help us to determine the level of exposure of the city to severe events. They used the model of centered betweenness, which typically calculates nodes or edges to be used to correlate any pair of nodes. This network-topology indicator can obtain some characteristics of the robustness of the transportation network. In addition, the center between the points is a structural-significance indicator based on the global data of the shortest path that links every pair of nodes. The node or edge betweenness signifies the shortest path throughout the node or edge [39]. Nodes or edges having much higher values than the average appear to be more central in relation to their neighbors, suggesting that the others depend on these nodes or edges in making connections within the transportation network. The edge-betweenness centrality model can incorporate the relative importance of roadway sections into the prioritization of postdisaster roadway networks for restoration, and it is an essential part of the transportation network.

Given such notable characteristics of the node- and edge-betweenness centrality models, these two modeling approaches appear to be naturally applicable to our research problems. They can be comparatively developed to analyze road network patterns as well as the robustness of transportation networks. Previous studies studied how and why systems respond to interference, all from different perspectives. In the event of higher interference, the system becomes more resilient and may be able to respond and recover $[40,41]$.

Moreover, to recognize the robustness of the system, understanding is essential in the response curve and recovery level. De Bruijn [41] suggested aspects of system robustness, as it demonstrates how the system responds to interference at different levels. A more gradual curve indicates that floods are more frequent, so people are expected to be better prepared. High resistance thresholds often coincide with low proportions, as well-protected areas attract socioeconomic development. The probability of flooding may be minimal, but one large flood will have a significant impact. A robust system is one in which the response curve is far from the recovery criteria for a wide range of noise sizes.

\section{Methodology}

This study used the framework of Mens et al. [11] for evaluating system robustness. In this study, the four-stage framework was adopted and refined before being empirically employed to systematically quantify urban road network robustness against floods.

Figure 2 shows the steps to be taken when analyzing system robustness: (1) specifying the system and disturbance (i.e., transportation and flood-risk system), (2) illustrating the system response in terms of the damaged area as a function of floodwater levels 
and protection measures, (3) determining recovery thresholds based on land use and socioeconomic system functionality, and (4) quantifying robustness through the application of the edge- and node-betweenness centrality models [11].

Step 1: Specifying the system and disturbance

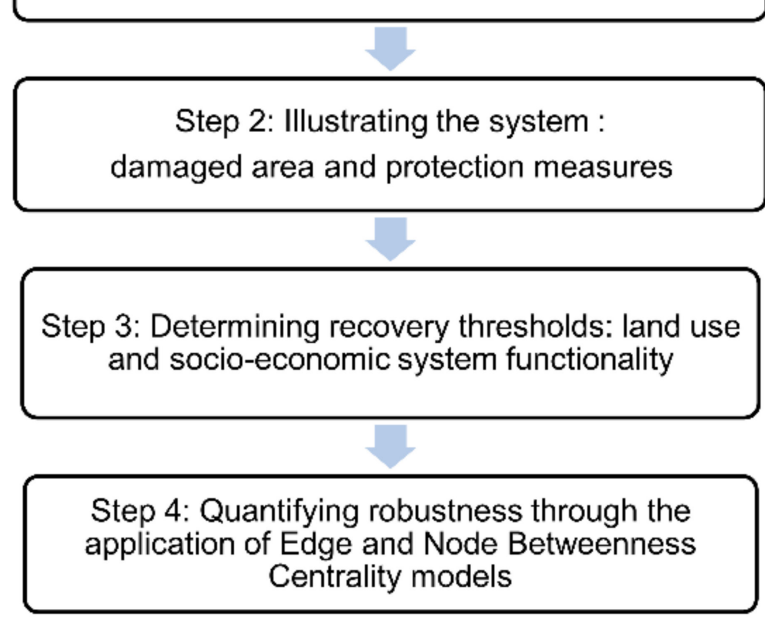

Figure 2. A conceptual framework for analyzing system robustness (modified from [11]).

3.1. Step 1: Specifying the System and Disturbance (i.e., Identifying Chiang Mai's Road Network or Transportation Together with Flood-Risk System)

Disturbances are defined as discontinuous events at times that disrupt ecosystems, communities, and population structures [42]. Therefore, floods are the primary form of natural disturbances. In this step, we define the systems that are considered and the type of disturbance and causing of floods, such as local flooding, riverine floods, coastal floods, and flash floods.

\subsection{Step 2: Illustrating the System Response in Terms of the Damaged Area as a Function of Floodwater Levels and Protection Measures}

Response to flooding is vital because if we can respond to flooding quickly enough, it will significantly reduce the flood impact. If we can present the response to the affected person or affected areas, it will help to respond immediately to areas of large impact. If there are no affected persons or affected areas of flooding, the system response is zero. The response depends on the level of the disturbance as well as on the system attributes.

\subsection{Step 3: Determining Recovery Thresholds Based on Land Use and Socioeconomic System Functionality}

Recovery of flood-risk systems means the progression of returning to a usual condition after flooding. Recovery capacity is the ability to organize, repair, and reconstruct. The long-term impact of a flood event depends on the recovery time, depending on the recovery capacity. Recovery features are defined as system-specific aspects that affect the ease of recovery $[9,43]$. Therefore, the degree of recovery can be inferred from preflood and postflood system conditions, identified by key system characteristics such as population, labor, availability of drinking water, and access to food and electricity. There are four degrees of recovery: recovery, recovery and betterment, partial recovery, and no recovery (Figure 3). 


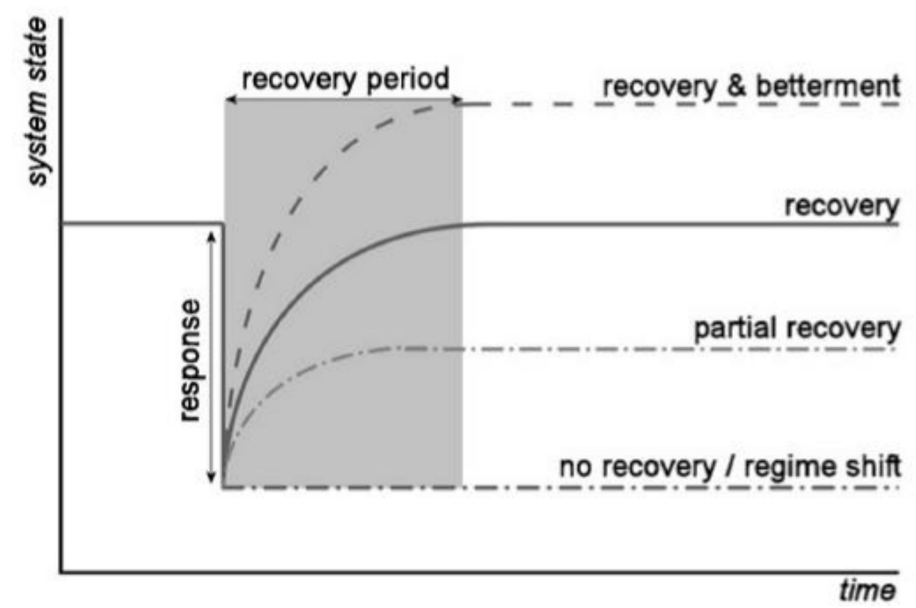

Figure 3. System state as a function of time, in response to a flood event, showing four degrees of recovery. [11].

\subsection{Step 4: Quantifying Robustness through the Application of Edge- and Node-Betweenness Centrality Models}

To understand system robustness, it can be explained through four characteristics:

1. Resistance threshold: determined by the reverse phase of the highest interference level, which response is zero.

2. Severity of the response: represents the effect of the disruption-level range. It is challenging to estimate severity in a single number, as it depends on the interruption level and the response variable selected. For flood-risk systems, previous studies used the predictable annual damage and the predictable number of deaths per year to specify the severity of the response. It is equal to the flood risk and can be considered as the area under the response curve when the trouble is stated in terms of the possibility of the flood [40,41].

3. Response proportion: To measure the proportion of the response or evaluate the effect of flooding on the resilience of the transport network, the model of betweenness centrality is used, which measures the likelihood of node or edge to be used to link any pair of nodes. This network topology can capture portions of the response. Overall, the central structure indicator between the centers is based on global information of the shortest path connecting all node pairs. A node or edge with high probability indicates the shortest path through that node or edge [44]. The node or edge that has a value between very high altitudes can play an important role in the network and is an essential part of the network in disrupting the situation if there are no other routes in the network. It is often used as one of the most representative indicators of a network center [45]. The evaluation of the response proportions can be calculated from the following equation.

A roadway network $G$ comprises $m$ nodes and $n$ road sections with nodes $s, t \in N$ and section $e_{i j} \in E$, where $N$ is a set of nodes, and $E$ is a set of sections. In mathematics, edge-betweenness centrality and node-betweenness centrality are defined as [39]:

Edge-betweenness centrality $E B\left(e_{i j}\right)$ of the section $e_{s t}$ between node $s$ and node $t$ is denoted by:

$$
E B\left(e_{i j}\right)=\sum_{\substack{s, t \in N \\ s \neq t, i \neq j}}\left[\frac{\sigma_{s t}\left(e_{i j}\right)}{\sigma_{s t}}\right]
$$

where $\sigma_{s t}\left(e_{i j}\right)$ is the total number of shortest paths between node $s$ and node $t$ that pass through a section $e_{i j}$, and $\sigma_{s t}$ is the total number of shortest paths between node $s$ and node $t$. 
Node-betweenness centrality $N B(i)$ of a node $i$ is defined as [18]:

$$
N B(i)=\sum_{s \neq i \neq t \in V}\left[\frac{\sigma_{s t}(i)}{\sigma_{s t}}\right]
$$

where $\sigma_{s t}(i)$ is the number of those paths that pass through the node $i$, and $\sigma_{s t}$ is the total number of shortest paths from node $s$ and node $t$.

In general, we can indicate that node-betweenness centrality allows us to measure the amount of traffic or the amount of traffic that moves through each intersection and road section [46], and it can be used as a measure of the influence that nodes have on the spread of information across the entire network. Therefore, in this study, we used the edgebetweenness centrality and node-betweenness centrality for measuring the proportionality of the response.

4. Point of no recovery: To reach this point, we need a recovery basis for each response variable. Little is known about this issue, and it is likely not the point of difference but is it a gradual process or "the area with no recovery" instead. However, the study of the response related to the possible criteria is expected to provide insights into the level of the flood. First, we recommend the following recovery criteria for response variables: affected area, affected link, and affected node. If these criteria are exceeded, the recovery will be challenging, and regime changes may occur. Thus, the unrecoverable point can be measured by the return time of the trouble magnitude at which the response curve intersects with the assumed recovery threshold.

\section{Results}

In this study, the application of a framework for evaluating system robustness was employed to systematically quantify the flood resilience of urban road networks in Chiang Mai, Thailand.

Chiang Mai has an area of approximately $20,107.057 \mathrm{~km}^{2}$ and an area of land use of $408.09 \mathrm{~km}^{2}$. It is the largest province in northern Thailand. The general topography is mountainous with plains in the middle along the Ping River. It has an estimated population of 1.76 million people, the fifth-largest in the country, of which 960,000 live in urban and suburban areas (Figure 4). Since Chiang Mai is the center of northern Thailand in commerce, industry, tourism, education, and transportation, it is facilitated by several transportation modes such as railways, roadways, waterways, and airways.

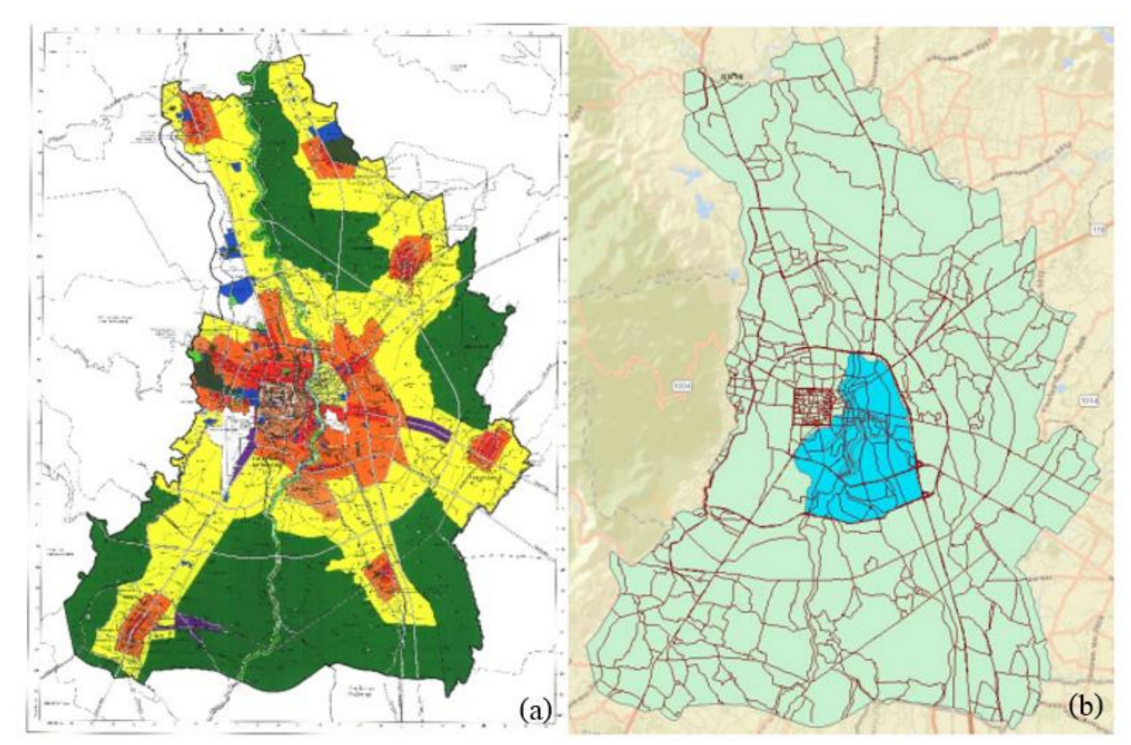

Figure 4. (a) Map of land use in Chiang Mai $\left(408.09 \mathrm{~km}^{2}\right.$ ) (source from: Department of Public Works and Town \& Country Planning, 2021); (b) flooding (25.83 km²). Data from 1994, 1995, and 2005. 
This case study aims to measure the urban road network robustness of the Chiang Mai flood-risk system and to explore alternative configurations. Hydrodynamic and damage models were developed to calculate the robustness indicators. Then, the Chiang Mai flood-risk system was modeled using flooding simulations, and the resulting flood-depth maps were created.

4.1. Step 1: Specifying the System and Disturbance (i.e., Identifying Chiang Mai's Road Network, or Transportation and Flood-Risk System)

In Thailand, the flooding season starts around July every year. The arrival of tropical storms and heavy monsoons between July and October of every year results in heavy rains, landslides, flash floods, and river flooding [47]. At the start of the monsoon season, the first floods occur in the northern part of Thailand. The excess water drains into the Ping River, providing the largest and the most important river basin in the northern part of Thailand.

For Chiang Mai, the largest city in northern Thailand, the main cause of the flooding is local flooding. There are many reasons for flooding in Chiang Mai Province, including: (1) a large amount of rainfall that both falls within the city and comes from outside the city, which accumulate together; (2) the forest area in the upstream area has declined to become commercial agricultural areas, causing the water from the upstream area to flow down with urban water, which is lowland and flood plain until the amount of water exceeds that of the Ping River, which will then overflow and flood; (3) invasion of the Ping River has greatly narrowed the size of the river from the past, which is found mostly in the area of the bridge over the Ping River, a super highway road to the area of Provincial Police Station 5; (4) the construction of roads with insufficient drainage systems, lead to flooding in the Chiang Mai municipality area; and (5) a narrower and shallower river channel caused by bridge foundations built in the river [48].

Chiang Mai transport consists of several transportation systems: land, rail, and air. There are several types of road networks: radial road, ring road, primary provincial road, secondary provincial road, district road, and L-railway local road [49]. Additionally, flooding impacts in several ways, through both direct impacts (e.g., physical damage to transport infrastructure) and indirect impacts (e.g., disruption to traffic flow, business interruption, increased emissions) [50-52].

\subsection{Step 2: Illustrating the System Response in Terms of the Damaged Area as a Function of Floodwater Levels and Protection Measures}

Figure 5 shows the estimation of the damaged areas that coincide with the water level in Chiang Mai. It indicates that the water level and the number of affected areas formed a direct relationship in that as the water level increased, the number of the affected areas also increased, and vice versa (Figure 5). High amounts of water flowing in streams, consequently increasing the water depth and water pressure, often lead to flooding.

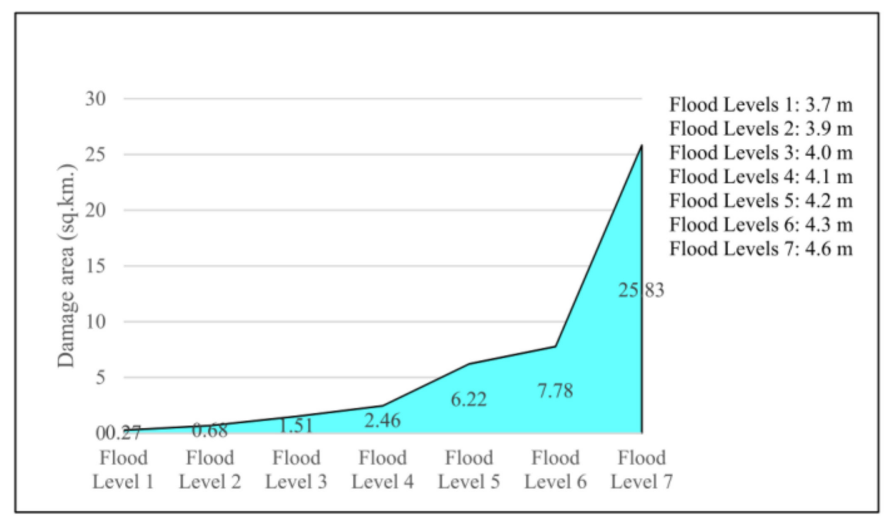

Figure 5. The damaged area increased with increasing water. 
In the "water wall on the bank of the Ping River", no flooding occurred until a disturbance of $3.7 \mathrm{~m}$. When this resistance was exceeded, only the subareas with a relatively lower economic value were flooded. At a disturbance level of $4.3 \mathrm{~m}$, the better-protected areas were flooded as well. Compared to the current configuration, the water wall on the bank of the Ping River had the same resistance threshold but a smaller response for disturbances between 3.7 and $4.3 \mathrm{~m}$. In the "spatial planning" configuration, the affected area and the economic losses were relatively lower when the disturbances were greater than $3.7 \mathrm{~m}$. Thus, the resistance threshold was set to that of the current situation. Note that the spatial planning in this case only implied flood-proof buildings, and did not include people motivated to migrate to the low-risk zones; hence it only affected the economic damages and not the number of affected persons.

\subsection{Step 3: Determining Recovery Thresholds Based on Land Use and Socioeconomic System Functionality}

Recovery of flood-risk systems means the progression of returning to a usual condition after flooding [9,43]. Therefore, the degree of recovery can be inferred from preflood and postflood system conditions, identified by key system characteristics such as population, labor, availability of drinking water, and access to food and electricity. The recovery level of the damaged areas was proposed at $6.33 \%$ of Chiang Mai Province, equaling 233,632 affected persons (density 1533.01 persons $/ \mathrm{km}^{2}$ ) at a water level of $4.7 \mathrm{~m}$ (level 7). Although only $6.33 \%$ of the areas were affected $\left(408.09 \mathrm{~km}^{2}\right)$, these are economically important districts in terms of trading, education, healthcare, and transportation systems. It is a community for farmers to bring agricultural products for sale. A total of 21 schools ranging from kindergarten to high school are also located in this area, with approximately 46,800 students. Additionally, a large hospital, McCormick Hospital, which treats 400 inpatients and serves approximately 500 outpatients per day, is located in this zone. Last but not least, this area also includes the bus terminals of Chiang Mai Province.

From the quantified thresholds, the recovery threshold of the affected area can be considered as the indicative point of no recovery. Then, this point of no recovery is utilized as the maximum water level for calculating the node and link damage curve. On the other hand, the resilience of transport can be determined in specific areas where nodes and links are most affected, to the point of not being affected or the point of normal condition before flooding.

\subsection{Step 4: Quantifying Robustness through the Application of Edge- and Node-Betweenness Centrality Models}

The results of the road-network analysis by edge-betweenness and node-betweenness that indicated the network of roadways at the edge or link with high to low traffic conditions are shown in Figure 6 as red, pink, brown, yellow, and green lines, respectively. A node or intersection with high traffic conditions is presented as a large circle, while a smaller circle is considered a lower traffic condition (Figure 6). 

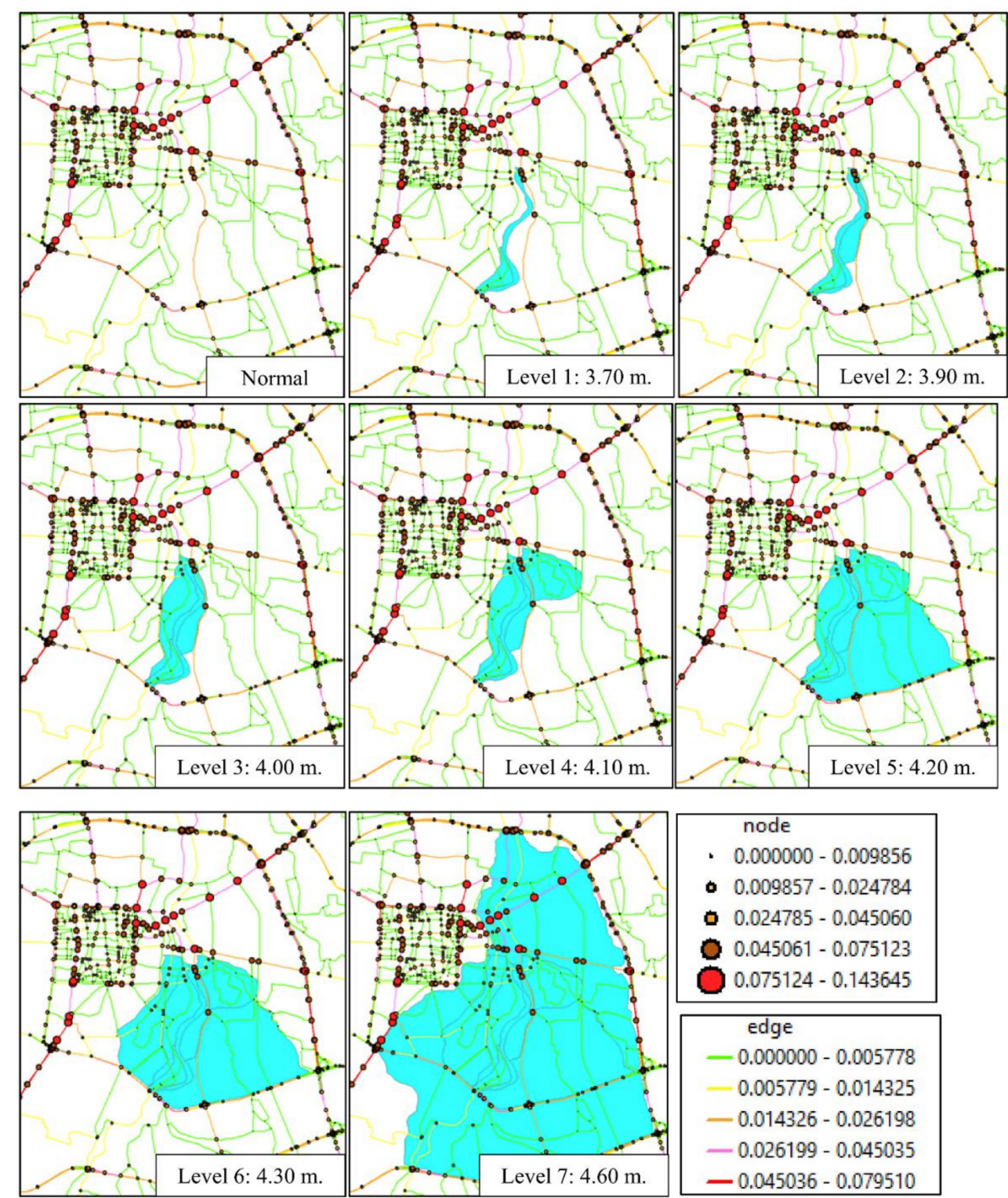

Figure 6. Study area with an indication of the flood extent and flood depths.

Moreover, the application of edge- and node-betweenness centrality models showed that the number of affected links (Figure 7a), nodes (Figure 7b), and cars (Figure 7c) also increased according to the rising water level. 

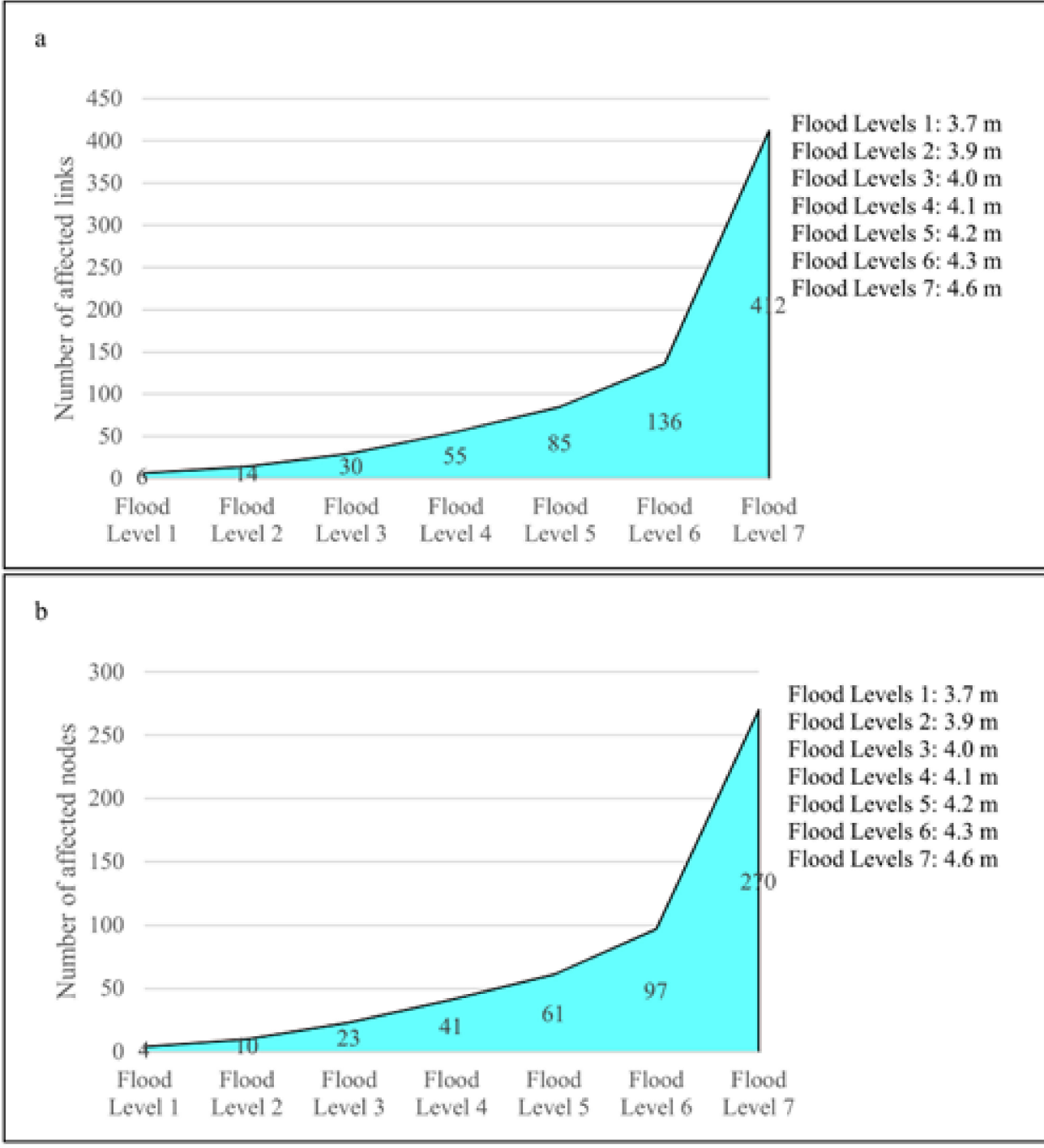

c

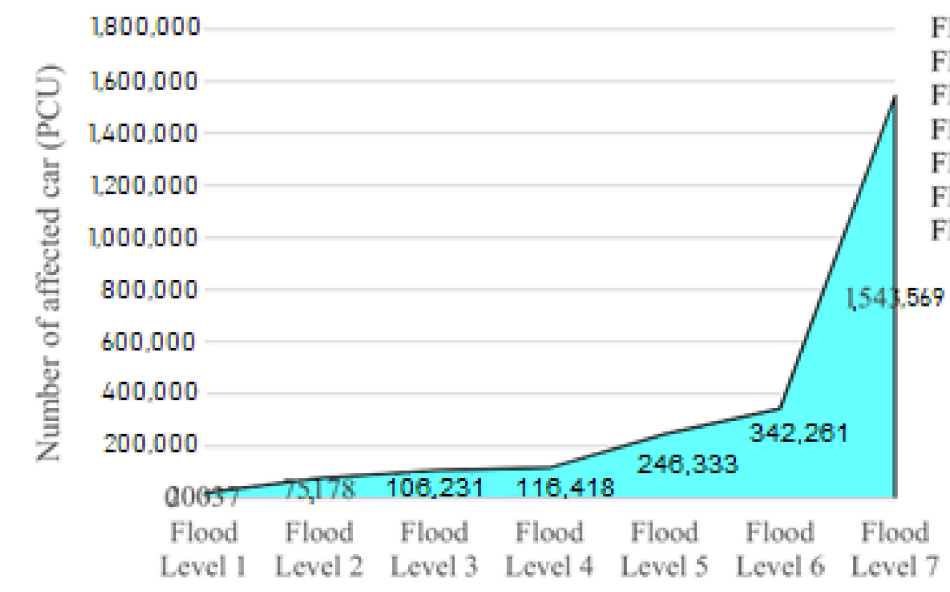

Figure 7. Response curves for the current and alternative system configurations, including the recovery threshold: (a) number of affected links, (b) number of affected nodes, and (c) number of affected cars (PCU). 


\section{Discussion}

In this study, the edge- and node-betweenness centrality models are presented as a new methodology to evaluate the resilience of transportation during floods. In previous research on Shijiazhuang in China [39], it was recognized that an edge-betweenness centrality model can corporate the relative importance of roadway sections into the prioritization of postearthquake urban roadway networks for restoration. They used the shortest paths of the edge- and node-betweenness centrality models to define the dynamic network, and used node and edge measures to analyze the topology of transportation networks [53,54]. The edge-betweenness centrality model has the potential of not only obtaining the weight of each roadway section of a large-scale roadway network, but also of conducting the resource allocation for restoring the postearthquake urban roadway network. According to previous research, we employed the edge-betweenness centrality model to evaluate the resilience of transportation and model the relative importance or weight of a roadway section in support of the restoration during flood.

In a previous study, Kermanshah and Derrible, [18] indicated that they adopted a deterministic approach to simulate extreme flooding events in two cities, New York City, NY, and Chicago, IL, by removing entire sections of road systems used in the US. They measured changes in the number of real trips that could be completed (using travel-demand data), Geographical Information System (GIS) properties, and network topological indicators. They notably measured and discussed how betweenness centrality is redistributed after flooding. Broadly, robustness in spatial systems like road networks is dependent on many factors, including topological structure of the network and system size (number of nodes and links). Similar to the study in New York City and Chicago, in this study we also used the number of nodes and links from the edge-betweenness centrality model as an indicator of robustness or resilience of transportation after flooding.

In this study, the robustness indicators shown in the system response curve (Figure 7) can provide useful information for decision-makers to manage flood risk. Through a series of explanations about the conceptual framework, planners can then develop tools to quantify road-network robustness towards flood-resilient transportation systems. In addition, this study describes how to quantify the response of a flood-risk system in terms of the damaged area, the number of affected links, and the number of affected nodes. The response curve is a great spot to start discussing the strength of a system. The response curves of alternative system configurations can be compared to the current configuration, and all tolerance characteristics can be quantified.

Moreover, some studies indicated that they found a high correlation between traffic flow obtained using an augmented betweenness centrality measure and traffic flow obtained using a state-of-the-art traffic-assignment model. They suggested a new trafficassignment model that was based on the concept of the shortest path betweenness centrality measure, borrowed from the domain of complex network analysis. They showed how betweenness can be augmented to solve the traffic-assignment problem given an arbitrary travel cost [55]. In this study, we can indicate that the number of affected cars obtained using edge- and node-betweenness centrality models can solve the traffic-assignment problem during and after flooding.

This study defines the strength of the transportation system as the ability to function under a wide range of flooding-disruption levels. In the robustness analysis, the responseand-recovery systems over a wide range of flooding in each level are shown in the response curve, with four properties described as the threshold of resistance, the severity of response, response proportions, and point of no recovery. From the conceptual framework, we believed that the point of no recovery would be pushed further away at a lower response curve by implementing a consequence-reduction flood-protection project. One of the recommended indicators is the point of no recovery. In Chiang Mai, the point of no recovery is only influenced by the water wall on the bank of the Ping River. The point of no recovery can be revealed if one of the recovery thresholds is exceeded. For example, the amount of the affected area exceeds $6.33 \%$ of the people at a disturbance level of $4.6 \mathrm{~m}$ 
(local flooding level). At that point, the recovery threshold has not been exceeded yet. However, it will reach the point of no recovery when links and nodes cannot function.

This study broadly describes how to set the recovery criteria from the response curve. Less or more disruption will be highly dependent on the recovery threshold, where less to more disruption occurs between normal conditions before flooding and at a rising water level. Therefore, it is very important for decision-makers when setting goals for managing flood-risk disaster that these criteria be examined. This study is similar to previous studies in that they also used the edge-betweenness centrality model and integrated the relative importance or weight of each roadway section in the restoration of a postdisaster urban roadway network [18,53-57]. The findings of this study can be used to provide decisionmaking support for road-network management, planning, and optimization of urban traffic construction. Additionally, we suggested further study to compare the strength of other flood-resilient transportation systems.

\section{Conclusions}

Managing flood risk in transportation systems is very complex and essential for relevant organizations. This study presented a methodology to help decision-makers assess the resilience of transportation during a flood situation. A framework for analyzing system robustness was developed to quantify flood resilience of urban roadway networks in Chiang Mai, Thailand as a case study. Response curves for the current and alternative system configurations, including the recovery threshold, were described based on three significant variables: the affected links, nodes, and cars during a flood situation. The results of this study contribute to sustainability in preventing and solving traffic problems during floods, which in the end can sustainably reduce the effects of flooding, such as economic, health, and education impacts during the event of flooding. Other variables mainly affected by floods also can be developed as flood-risk criteria for transportation. Those variables and their thresholds can be set differently based on resources, budgets, and technical constraints in each organization.

Author Contributions: Conceptualization, S.T. and K.A.; writing—original draft preparation, S.T. and K.A.; methodology, S.T.; formal analysis, S.T.; investigation, S.T.; data curation, S.T.; visualization, S.T.; writing—review and editing, A.U., N.K., and K.A.; supervision, K.A. All authors have read and agreed to the published version of the manuscript.

Funding: This project received funding from a graduate school research scholarship from Chiang Mai University, Thailand, in 2018.

Institutional Review Board Statement: Not applicable.

Informed Consent Statement: Not applicable.

Data Availability Statement: Not applicable.

Acknowledgments: This research work was partially supported by Chiang Mai University, Thailand. The first author would like to express an appreciation to the Graduate School, Chiang Mai University, Thailand for the financial support during his PhD degree study at Chiang Mai University, in which the research work is done.

Conflicts of Interest: The authors declare no conflict of interest.

\section{References}

1. Vos, F.; Rodriguez, J.; Below, R.; Guha-Sapir, D. Annual Disaster Statistical Review 2009: The Numbers and Trends; Centre for Research on the Epidemiology of Disasters (CRED): Brussels, Belgium, 2010.

2. Jha, A.; Lamond, J.; Bloch, R.; Bhattacharya, N.; Lopez, A.; Papachristodoulou, N.; Bird, A.; Proverbs, D.; Davies, J.; Barker, R. Five Feet High and Rising: Cities and Flooding in the 21st Century; The World Bank: Washington, DC, USA, 2011.

3. Du, W.; Fitzgerald, G.J; Clark, M.; Hou, X.-Y. Health Impacts of Floods. Prehospital Disaster Med. 2010, 25, 265-272. [CrossRef] [PubMed]

4. Kotzee, I.; Reyers, B. Piloting a social-ecological index for measuring flood resilience: A composite index approach. Ecol. Indic. 2016, 60, 45-53. [CrossRef] 
5. Boonyabancha, S.; Archer, D. Thailand's Floods: Complex Political and Geographical Factors behind the Crisis; International Institute for Environment and Development: London, UK, 2011; Available online: https: / www.iied.org/thailands-floods-complex-politicalgeographical-factors-behind-crisis (accessed on 19 January 2021).

6. Tamvakis, P.; Xenidis, Y. Resilience in Transportation Systems. Procedia Soc. Behav. Sci. 2012, 48, 3441-3450. [CrossRef]

7. Shen, Z.-J.M.; Pannala, J.; Rai, R.; Tsoi, T.S. Modeling Transportation Networks during Disruptions and Emergency Evacuations; University of California Transportation Center: Berkeley, CA, USA, 2008.

8. De Vale, J. Measuring Operating System Robustness; Carnegie Mellon University, Institute for Complex Engineered Systems: Pittsburgh, PA, USA, 2000.

9. De Bruijn, K.M. Resilience and Flood Risk Management: A Systems Approach Applied to Lowland Rivers; TU Delft: Delft, The Netherlands, 2005.

10. Markolf, S.A.; Hoehne, C.; Fraser, A.; Chester, M.V.; Underwood, B.S. Transportation resilience to climate change and extreme weather events-Beyond risk and robustness. Transp. Policy 2019, 74, 174-186. [CrossRef]

11. Mens, M.J.; Klijn, F.; De Bruijn, K.M.; Van Beek, E. The meaning of system robustness for flood risk management. Environ. Sci. Policy 2011, 14, 1121-1131. [CrossRef]

12. Valenzuela, Y.B.; Rosas, R.S.; Mazari, M.; Risse, M.; Rodriguez-Nikl, T. Resilience of Road Infrastructure in Response to Extreme Weather Events. In Proceedings of the International Conference on Sustainable Infrastructure 2017, New York, NY, USA, 26-28 October 2017; pp. 349-360.

13. Sullivan, J.L.; Novak, D.C.; Aultman-Hall, L.; Scott, D.M. Identifying critical road segments and measuring system-wide robustness in transportation networks with isolating links: A link-based capacity-reduction approach. Transp. Res. A Policy Pract. 2010, 44, 323-336. [CrossRef]

14. Miller-Hooks, E.; Zhang, X.; Faturechi, R. Measuring and maximizing resilience of freight transportation networks. Comput. Oper. Res. 2012, 39, 1633-1643. [CrossRef]

15. Rodríguez-Núñez, E.; García-Palomares, J.C. Measuring the vulnerability of public transport networks. J. Transp. Geogr. 2014, 35, 50-63. [CrossRef]

16. Restemeyer, B.; Woltjer, J.; Van Den Brink, M. A strategy-based framework for assessing the flood resilience of cities — A Hamburg case study. Plan. Theory Pract. 2015, 16, 45-62. [CrossRef]

17. Faturechi, R.; Miller-Hooks, E. Measuring the performance of transportation infrastructure systems in disasters: A comprehensive review. J. Infrastruct. Syst. 2015, 21, 04014025. [CrossRef]

18. Kermanshah, A.; Derrible, S. Robustness of road systems to extreme flooding: Using elements of GIS, travel demand, and network science. Nat. Hazards 2016, 86, 151-164. [CrossRef]

19. Keating, A.; Campbell, K.; Szoenyi, M.; McQuistan, C.; Nash, D.; Burer, M. Development and testing of a community flood resilience measurement tool. Nat. Hazards Earth Syst. Sci. 2017, 17, 77-101. [CrossRef]

20. Campbell, K.A.; Laurien, F.; Czajkowski, J.; Keating, A.; Hochrainer-Stigler, S.; Montgomery, M. First insights from the Flood Resilience Measurement Tool: A large-scale community flood resilience analysis. Int. J. Disaster Risk Reduct. 2019, 40, 101257. [CrossRef]

21. Carpenter, S.R.; Walker, B.L.E.; Anderies, J.M.; Abel, N. From Metaphor to Measurement: Resilience of What to What? Ecosystem 2001, 4, 765-781. [CrossRef]

22. Morelli, A.B.; Cunha, A.L. Measuring urban road network resilience to extreme events: An application for floods. arXiv 2019, arXiv:1912.01739.

23. Bruneau, M.; Chang, S.E.; Eguchi, R.T.; Lee, G.C.; O’Rourke, T.D.; Reinhorn, A.M.; Shinozuka, M.; Tierney, K.; Wallace, W.A.; von Winterfeldt, D. A Framework to Quantitatively Assess and Enhance the Seismic Resilience of Communities. Earthq. Spectra 2003, 19, 733-752. [CrossRef]

24. Baroud, H.; Barker, K.; Ramirez-Marquez, J.E.; Rocco, S.C.M. Importance measures for inland waterway network resilience. Transp. Res. Part E Logist. Transp. Rev. 2014, 62, 55-67. [CrossRef]

25. Baroud, H.; Ramirez-Marquez, J.E.; Barker, K.; Rocco, C.M. Stochastic measures of network resilience: Applications to wa-terway commodity flows. Risk Anal. 2014, 34, 1317-1335. [CrossRef]

26. Hughes, J.; Healy, K. Measuring the Resilience of Transport Infrastructure; New Zealand Transport Agency Research Report 546; AECOM: Auckland, New Zealand, 2014.

27. Zhang, X.; Millerhooks, E.; Denny, K.G. Assessing the role of network topology in transportation network resilience. J. Transp. Geogr. 2015, 46, 35-45. [CrossRef]

28. Carlson, J.M.; Doyle, J. Complexity and robustness. Proc. Natl. Acad. Sci. USA 2002, 99, 2538-2545. [CrossRef] [PubMed]

29. Jen, E. Stable or Robust? What's the Difference? Robust Design: A Repertoire of Biological, Ecological, and Engineering Case Studies; Santa Fe Institute Studies on the Sciences of Complexity: Santa Fe, NM, USA, 2005.

30. Stelling, J.; Sauer, U.; Szallasi, Z.; Doyle, F.J., III; Doyle, J. Robustness of cellular functions. Cell 2004, 118, 675-685. [CrossRef] [PubMed]

31. Bankes, S. Exploratory Modeling for Policy Analysis. Oper. Res. 1993, 41, 435-449. [CrossRef]

32. Ben-Haim, Y. Info-Gap Decision Theory: Decisions under Severe Uncertainty; Elsevier: Amsterdam, The Netherlands, 2006.

33. Lempert, R.; Popper, S.; Bankes, S. Shaping the Next One Hundred Years: New Methods for Quantitative, Long-Term Policy Analysis; RAND Corporation: Santa Monica, CA, USA, 2003. 
34. Rosenhead, J.; Elton, M.; Gupta, S.K. Robustness and optimality as criteria for strategic decisions. J. Oper. Res. Soc. 1972, 23, 413-431. [CrossRef]

35. Salido, M.A.; Barber, F.; Ingolotti, L. Robustness in railway transportation scheduling. World Congr. Intell. Control Autom. 2008, 2880-2885. [CrossRef]

36. Policella, N. Scheduling with uncertainty: A proactive approach using partial order schedules. AI Commun. 2005, 18, 165-167.

37. Takeuchi, Y.; Tomii, N. Robustness indices for train rescheduling. In Proceedings of the 1st International Seminar on Railway Operations Modelling and Analysis (CDROM), Delft, The Netherlands, 8-10 June 2005.

38. Cats, O.; Jenelius, E. Planning for the unexpected: The value of reserve capacity for public transport network robustness. Transp. Res. Part A Policy Pr. 2015, 81, 47-61. [CrossRef]

39. Wang, X.; Zhou, Y.; Han, Z.; Zhang, Z. A Spatial Approach to Resource Allocation for Post-Earthquake Restoration of Urban Roadway Networks. In Proceedings of the TRB 95th Annual Meeting, Washington, DC, USA, 10-14 January 2016.

40. De Bruijn, K. Resilience and flood risk management. Hydrol. Res. 2004, 6, 53-66. [CrossRef]

41. De Bruijn, K.M. Resilience indicators for flood risk management systems of lowland rivers. Int. J. River Basin Manag. 2004, 2, 199-210. [CrossRef]

42. Townsend, C.R.; Hildrew, A.G. Species traits in relation to a habitat templet for river systems. Freshw. Biol. 1994, 31, 265-275. [CrossRef]

43. Marchand, M. Modelling coastal vulnerability: Design and evaluation of a vulnerability model for tropical storms and floods. Ios Press 2009, 5, 101-104.

44. Duan, Y.; Lu, F. Structural robustness of city road networks based on community. Comput. Environ. Urban Syst. 2013, 41, 75-87. [CrossRef]

45. Derrible, S. Network Centrality of Metro Systems. PLoS ONE 2012, 7, e40575. [CrossRef]

46. Borgatti, S.P. Centrality and AIDS. Connections 1995, 18, 112-115.

47. TMD. Thai Meteorological Department. Amount of Rainfall in Thailand in 2020. Available online: http://www.tmd.go.th (accessed on 29 November 2020).

48. Kumcumphet, P. Guidelines for Flood Protection in Nakhon Chiang Mai municipality. Master's Thesis, Chulalongkorn University, Bangkok, Thailand, 2007.

49. Jittrapirom, P. An Analysis of Chiang Mai City's Transport System and Its Path Towards Sustainability, with a Focus on the Role of the Motorcycle and the Shared-Taxi. Ph.D. Thesis, Vienna University of Technology, Vienna, Austria, 2015.

50. Brown, S.; Dawson, R. Building network-level resilience to resource disruption from flooding: Case studies from the Shetland Islands and Hurricane Sandy. E3s Web Conf. 2016, 7, 04008. [CrossRef]

51. Hammond, M.J.; Chen, A.S.; Djordjevic, S.; Butler, D.; Mark, O. Urban flood impact assessment: A state-of-the-art review. Urban Water J. 2015, 12, 14-29. [CrossRef]

52. Walsh, C.L.; Ford, A.C.; Barr, S.; Dawson, R.J. A spatio-temporal modelling framework for the integrated assessment of cities. Proceedings of Earth Systems Engineering 2012: A Technical Symposium on Systems Engineering for Sustainable Adaptation to Global Change, Newcastle, UK, 3-5 July 2012.

53. Lordan, O.; Sallan, J.M. Dynamic measures for transportation networks. PLoS ONE 2020, 15, e0242875. [CrossRef]

54. Zuo, Z.; Wang, T.; Pan, X. Identification of key nodes and links based on road network reliability: A case study of Urumqi. Transp. Stand 2015, 1, 18-24.

55. Puzis, R.; Altshuler, Y.; Elovici, Y.; Bekhor, S.; Shiftan, Y.; Pentland, A. Augmented betweenness centrality for environmentally aware traffic monitoring in transportation networks. J. Intell. Transp. Syst. 2013, 17, 91-105. [CrossRef]

56. Liu, W.; Li, X.; Liu, T.; Liu, B. Approximating betweenness centrality to identify key nodes in a weighted urban complex transportation network. J. Adv. Transp. 2019, 1, 1-8. [CrossRef]

57. Lin, J.; Ban, Y. Complex network topology of transportation systems. Transp. Rev. 2013, 33, 658-685. [CrossRef] 